\title{
Secondary Students' Views of Climate Change in Hong Kong
}

\author{
Liz Jackson and Ming-Fai Pang \\ University of Hong Kong
}

\begin{abstract}
:
Though there has been an increased focus on climate change in Hong Kong's educational policy and curriculum over the last decade, little is known about the impact of curricular implementation on young people's environmental and climate change-related views, attitudes, awareness, or behaviors. This paper examines the state of climate change education in Hong Kong based on findings from a multi-pronged investigation. The main research questions addressed are: (1) What are Hong Kong secondary students' understandings of and attitudes towards climate change issues?, and (2) Is there any significant difference between students studying in local and international schools in Hong Kong? The paper provides a content analysis of climate change curriculum in local and international schools, and reports on a large-scale survey of international and local school students' environmental attitudes, and qualitative interviews of their awareness and behaviors related to climate change. We conclude with reflections on the implications of this study for climate change education in Hong Kong in the future and vital areas for further research.
\end{abstract}

Key words: climate change education, Hong Kong, secondary schooling, environmental attitudes, climate change

Author info:

Liz Jackson is Assistant Professor of Education and Deputy Director of the Master of Education Programme at the University of Hong Kong.

Ming-Fai Pang is Associate Professor at the Faculty of Education, the University of Hong Kong, specializing in the areas of phenomenography, variation theory and lesson/ learning study.

Introduction

The twin issues of sustainability and climate change highlight the indisputable depletion of the earth's natural resources and its consequences, against a backdrop of 
excessive consumerism. Thus, the field of Education for Sustainable Development (ESD) emerged as a major area of educational research to aid societies in responding to this need. ESD is a broad interdisciplinary field that includes features such as learning environmental knowledge in the classroom, spending time in nature, promoting a sense of responsibility for the environment, and participating in environmental issues at local and global levels (Jackson, 2016). Climate change education (CCE) is a sub-area of ESD; it is focused on the complexity and challenges related to understanding and responding to the impact of climate change (UNESCO, 2010b).

Though there has been an increased interest on ESD and CCE in Hong Kong's educational policy and curriculum over the last decade, little is known about the impact of this implementation on young people's environmental and climate change-related views, attitudes, awareness, or behaviors. This paper then examines the state of climate change education in Hong Kong based on findings from a multi-pronged investigation, which includes a content analysis of CCE in curricular documents, a large-scale survey of students' environmental attitudes, and qualitative interviews of their awareness and behaviors related to climate change. We conclude with reflections on the implications of this study for CCE in Hong Kong in the future and vital areas for further research.

\section{Background}

\section{Curriculum Overview}

In Hong Kong, CCE has been increasingly included in formal curricula and nonformal programs of local and international schools (typical of the respective school types in Hong Kong more broadly), over the last few decades, in line with international trends of growing concern with global climate change. In the local curriculum, students receive CCE through Liberal Studies, Science and Geography. Liberal Studies is a compulsory 
subject in senior forms (Forms 4-6). Science is offered in junior forms (Forms 1-3). In senior forms, Biology is offered as an elective, a combined elective (taken either with Physics or Chemistry), or incorporated into Integrated Science. Similarly, Geography is offered in junior forms in most schools and becomes an elective in senior secondary level. In Liberal Studies, 12 hours is devoted to CCE. In Science, 86 total hours are devoted to CCE; in senior forms, students in Biology or Integrated Science study CCE for 6 or 47 hours respectively. In Geography, 84 hours are spent in junior forms and 195-220 hours in senior forms.

In the IB curriculum, CCE topics are discussed in the compulsory middle years' (Grades 7-10) Individuals and Society and Science and diploma years' electives (11-12) Geography, Environmental Systems and Society, and Biology. Middle years students do not follow a standardized curriculum; rather, the IB organisation provides suggested enquiry questions and topics for teachers to design classes flexibly according to local issues, student ability and student interest. In diploma years, students taking Geography spend 50-100 hours studying climate change knowledge. At the same time students can enrol in Environmental Systems and Society, or Biology; the former devotes 100 hours per year discussing climate change, while the latter devotes 30 hours.

Overall, the IB curriculum provides 80-330 hours of CCE while the local curriculum provides 182-488 hours (see Table 1).

\begin{tabular}{lcccc} 
& \multicolumn{4}{c}{ Curriculum } \\
\cline { 2 - 5 } \multicolumn{1}{c}{ Subjects } & \multicolumn{2}{c}{ Local } & \multicolumn{2}{c}{ IB } \\
\cline { 2 - 5 } & Form 1-3 & Form 4-6 & Grade 7-10 & Grade 11-12 \\
\hline Biology ${ }^{1}$ & - & $6.25^{*}$ & NS & $30^{*}$ \\
Environmental Systems and Society & - & - & - & $200^{*}$ \\
Geography & 84 & $195-220^{*}$ & NS & $50-100^{*}$
\end{tabular}




\begin{tabular}{|c|c|c|c|c|c|}
\hline \multicolumn{2}{|c|}{ Integrated Sciences } & 86 & $0-47^{*}$ & - & - \\
\hline \multicolumn{2}{|c|}{ Liberal Studies } & - & 12 & - & - \\
\hline \multirow{3}{*}{$\begin{array}{l}\text { Total Taught } \\
\text { Hours }\end{array}$} & No Elective & 170 & 12 & NS & $\mathbf{0}$ \\
\hline & With Elective & 170 & $12-318^{2}$ & NS & $80-330^{3}$ \\
\hline & Throughout School Life & \multicolumn{2}{|c|}{$182-488$} & \multicolumn{2}{|c|}{$80-330$} \\
\hline
\end{tabular}

Table 1 Total taught hours in lower and higher grades of CCE in local and IB curricula. Hours calculated by dividing number of relevant topics over irrelevant topics in the curriculum, then multiplied by total lesson time. 'NS' indicates no hours. Asterisk mark elective courses. Some subjects have a range of hours, depending on in-course elective units. Dash marks absence of subject.

Note 1: Biology is offered as a single elective or as a combined elective with other science subjects. Since elective units are not required in combined Biology curriculum, the relevant hours is shortened.

Note 2: Hours are with account to possible elective combinations. Minimum hours calculated assuming student does not take any relevant elective, maximum hours calculated assuming student takes Biology with Geography.

Note 3: Hours are with account to possible elective combinations. Minimum hours calculated assuming students only take Biology and Geography, maximum hours for all three electives.

There are additional ways students may engage CCE in both curricula. In Liberal Studies, students complete Independent Enquiry Study (IES) in Form 5 or 6. For senior Biology and Geography, an independent project is compulsory for school-based assessment, which requires 14 and 30 hours respectively. Local students thus potentially receive up to 126 hours of independent, investigative learning hours on CCE.

In the IB curriculum, environmental literacy is assessed through coursework, service, and examination. Diploma Years students of Geography, Environmental Systems and Society, and Biology submit annual investigative reports exploring a social or environmental phenomena, proposing solutions, etc. Time requirements for these projects are 30-38 hours for Biology, 30 for Environmental Systems and Society, and 20 for Geography. An Extended Essay course for Diploma Years and a Personal Project for Middle Years require students to study an environmental, community, or social issue every year; students thus spend up to 480 hours in Diploma Years, and up to 100 in their Middle Years studying independently about climate change. A CAS (Creativity, Action, 
Service) Project is mandatory: the social initiative project typically involves conservation, infrastructure building, or energy generation. Depending on the projects, student spend up to 500 hours throughout their 6 years in the IB Programme, learning CCE through hands-on projects (see Table 2).

Curriculum

Subjects

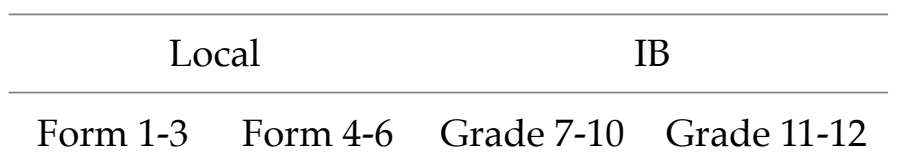

Independent Investigation

Biology

0

$14^{*}$

0

$30-48^{*}$

Environmental Systems and Society

$-$

$-$

$30^{*}$

Extended Essay / Personal Project

$-$

Geography

0

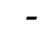

$100^{\circ}$

$300-480^{\circ}$

Integrated Sciences

0

$30^{*}$

0

$20^{*}$

Liberal Studies

$82^{\circ}$

\begin{tabular}{lcccc}
\hline CAS Project & - & - & $200^{\circ}$ & $300^{\circ}$ \\
\hline Total Possible Hours & $\mathbf{0}$ & $\mathbf{1 2 6}$ & $\mathbf{3 0 0}$ & $\mathbf{6 0 0 - 8 5 8}$
\end{tabular}

Table 2 Total experiential or independent learning hours on CCE in local and IB curricula. Total hours calculated with consideration of possible elective combinations. Asterisks mark elective courses. Circle represents hours subject to choice of topic.

\section{CCE Outcomes}

Despite curriculum developments in CCE in Hong Kong as discussed above, there has been scant academic or institutional research on the efficacy of CCE in impacting students' climate-related views or behaviors (Tsang \& Lee, 2014). A recent analysis revealed that numerous stakeholders in the society view climate change and other environmental-related discourse in Hong Kong as ill-informed, and the issue of sustainable development is poorly understood by the public. Broadly, ESD programmes have been being labeled as inefficient and underperforming (Hills, 2005). As the Hong 
Kong local school secondary curricula has undergone a reform in 2009 that impacts CCE, it is imperative that a new and accurate assessment of CCE programs and curricula be done (Jackson et al., 2016; Zhu, Douglas, \& Savelyeva, 2014).

For examining the impact of CCE and other environmentally-related educational initiatives and programs, researchers commonly analyze one of or a combination of three facets: knowledge, behavior, and/or attitudes. Testing knowledge can be painstaking; many questions need to be asked, and the most critical facts in the field can change quickly potentially inhibiting the research value over time (Vare \& Scott, 2007). This is particularly true in learning about climate change, as uncertainties mar curricular reductions of objective facts from political and scientific discourse. Further, behavior measurements are often biased, as they normally require self-reporting (Friesen \& Gangadharan, 2013). Behaviors might also be a result of necessity rather than a particular mindset. For instance, using public transport in many parts of the world is considered helpful in mitigating climate change. In Hong Kong, however, public transport is a necessity and does not correlate with climate change attitudes. Which behaviors matter most can also be difficult to analyze, teach about, and identify for education and educational research purposes (Jackson, 2016). Finally, attitudes are said to positively correlate to knowledge and behavior and tend not to change dramatically over time (Bamberg \& Möser, 2007; Kaiser, Wolfing \& Fuhrer, 1999; Scott \& Willits, 1994; Salehi, Nejad, Mahmoudi \& Burkart, 2016; for contrast, Jackson, et al., 2016; Subramanian, et al., 2016; Chan \& Chai, 2010).

The most frequently used analytical tool to measure climate change and other environmental-related attitudes, which we use in the current study, is the revised New Ecological Paradigm (NEP). The NEP was developed by American environmental sociologist Riley Dunlap and colleagues (Dunlap, 2008; Dunlap et al., 2000; Hawcroft \& 
Milfont, 2010). While Dunlap and colleagues claim cross-cultural suitability of the NEP, others question its suitability. Lee and colleagues found that Chinese and Japanese participants tend to answer more extremely to NEP questions expressing positive feelings but more neutrally for questions expressing negative feelings (2002). Another study found that Chinese and Japanese secondary students were more likely to answer neutrally than Americans (Chen, Lee \& Stevenson, 1995). Others suggest that local circumstances impact people's climate change attitudes (Jackson et al., 2016; Boeve-de Pauw, Donche, \& Van Petegem, 2011; Liu \& Constable, 2010). Gender has also been seen to be a factor related to climate change attitudes in many countries (World Bank, 2010; see also Hunter, Hatch, \& Johnson, 2004; Jackson et al., 2016).

To date there have been no large-scale studies of students' climate change-related attitudes at either the higher education or secondary level in Hong Kong. In 2003, Lai and colleagues administered the NEP to 229 people in Hong Kong and found their attitudes were within norms for other societies. Most recently, Cheung and colleagues (2016) used the NEP with 196 Hong Kong secondary school graduates enrolled in an associate degree programme in environmental studies. Again, mean scores were within an international normal range, and higher scores were correlated with more advanced environmental and climate change education.

Against this backdrop, our study seeks to measure climate change attitudes across a larger and more representative cross-section of young people in Hong Kong. The main research questions to be addressed are: (1) What are Hong Kong secondary students' understandings of and attitudes towards climate change issues?, and (2) Is there any significant difference between students studying in local and international schools in Hong Kong? In addition to the quantitative component (a survey based on the NEP questionnaire), the study has a qualitative component, as we conducted follow- 
up investigation interviews with a cross-section of surveyed students and their teachers regarding their awareness of and attitudes toward climate change issues in particular. Such information can enhance understanding of the impact of the contemporary curriculum in relation to CCE.

Methods

Data for the study was gathered through a survey and semi-structured interviews with secondary school students in Hong Kong. Conducted in 2015, the survey involved convenience sampling with of 1,383 students (out of a population of $64,000)$ from eleven (11) local schools and five (5) international schools. Gender, school banding and average income level of the school's district were factors for comparison. The survey had two parts: the NEP and 14 follow-up questions about students' experiences, knowledge, and behaviors. The follow-up questions targeted participants' sources of knowledge, their behaviors related to home life and family lifestyle, and their perception of the state of the environment and climate change in Hong Kong. Like the NEP, the follow-up questions also used the Likert scale, and were developed from other instruments for measuring environmentally related behaviors and knowledge, and refined after pretesting and piloting (Boeve-de Pauw, Donche \& Van Petegrem, 2011; Liu \& Constable, 2010; Subranmanian, et al., 2015).

Each question in the survey was provided in Traditional Chinese and English to avoid any misunderstandings due to language barriers. Surveys were completed using paper forms or online Google Docs, based on the preference of each school. All entries were exported and merged into a Microsoft Excel database. NEP scores were calculated using the raw scores. Raw scores ranged from strong NEP support (5) to neutral (3) to strong rejection (1) for positively worded questions, and in reverse for the negatively 
worded questions. We then tested whether mean NEP scores varied by gender, by type of school (local versus international) or by school 'banding' which correlates with student socioeconomic background.

Qualitative interviews were conducted in the spring of 2016 with 22 students from one local school and 12 students from one international school. Students came from varying secondary grades (from grades 7-12), and half were boys and half were girls. The focus of the interview was on their awareness of and attitude towards climate change issues. Furthermore, two teachers from each school who taught subjects most closely related to climate change and environmental education were interviewed, to understand their perspectives and teaching experiences. The two teachers from the local school were men, with Bachelor's degrees and Diplomas in education, and less than 5 years of teaching experience. The two teachers from the international school were both women with Bachelor's degrees and Diplomas in education. One had taught for less than 5 years while the other had taught for over 6 years. The interviews followed a semistructured format, were audio-recorded and transcribed. Conventional content analysis was adopted, in which the researchers used the emergent coding method (Stemler, 2001) to derive the categories or themes that were developed from the interview data collected.

Results and Analysis In this section, we first report the findings from the survey that we have conducted, to be followed by the results obtained from the interviews with the students and teachers in Hong Kong. 
The mean NEP score $(\mathrm{N}=1383$ ) was 3.62 (out of 5 ), indicative of a neutral to positive stand. Said score shows a fairly strong support of NEP statements in comparison with international studies, which tend to have scores lower than 3.50. This indicates that Hong Kong students seem to be more environmentally aware than other research participants. The Cronbach's alpha was calculated at 0.7031 , which is in line with the meta analysis average of all major NEP research studies undertaken in the last 30 years, of 0.71 (Hawcroft \& Milfont, 2010.) The percentages and mean scores of respondents to NEP statements are shown in Table 3.

\begin{tabular}{|l|l|l|l|l|l|l|}
\hline NEP Statement & $\begin{array}{l}\text { Strongly } \\
\text { agree }\end{array}$ & Agree & Neutral & Disagree & $\begin{array}{l}\text { Strongly } \\
\text { Disagree }\end{array}$ & $\begin{array}{l}\text { Mean } \\
\text { score }\end{array}$ \\
\hline $\begin{array}{l}\text { 1. We are approaching the limit of the } \\
\text { number of people the Earth can } \\
\text { support. }\end{array}$ & $23.79 \%$ & $47.35 \%$ & $22.41 \%$ & $5.87 \%$ & $0.94 \%$ & 3.87 \\
\hline $\begin{array}{l}\text { 2. Humans have the right to modify } \\
\text { the natural environment to suit their } \\
\text { needs. }\end{array}$ & $8.56 \%$ & $22.19 \%$ & $24.66 \%$ & $34.01 \%$ & $10.88 \%$ & 3.16 \\
\hline $\begin{array}{l}\text { 3. When humans interfere with nature } \\
\text { it often produces disastrous } \\
\text { consequences. }\end{array}$ & $23.71 \%$ & $55.47 \%$ & $15.81 \%$ & $4.71 \%$ & $0.58 \%$ & 3.97 \\
\hline $\begin{array}{l}\text { 4. Human ingenuity will insure that } \\
\text { we do not make the Earth unlivable. }\end{array}$ & $7.18 \%$ & $23.13 \%$ & $40.46 \%$ & $25.31 \%$ & $4.28 \%$ & 2.96 \\
\hline $\begin{array}{l}\text { 5. Humans are seriously abusing the } \\
\text { environment. }\end{array}$ & $39.74 \%$ & $49.02 \%$ & $8.77 \%$ & $2.03 \%$ & $0.80 \%$ & 4.24 \\
\hline $\begin{array}{l}\text { 6. The Earth has plenty of natural } \\
\text { resources if we just learn how to } \\
\text { develop them. }\end{array}$ & $24.87 \%$ & $44.53 \%$ & $19.07 \%$ & $10.66 \%$ & $1.23 \%$ & 2.19 \\
\hline $\begin{array}{l}\text { 7. Plants and animals have as much } \\
\text { right as humans to exist. }\end{array}$ & $46.19 \%$ & $37.42 \%$ & $11.24 \%$ & $3.70 \%$ & $1.81 \%$ & 4.22 \\
\hline $\begin{array}{l}\text { 8. The balance of nature is strong } \\
\text { enough to cope with the impacts of } \\
\text { modern industrial nations. }\end{array}$ & $3.63 \%$ & $11.68 \%$ & $26.11 \%$ & $45.11 \%$ & $13.85 \%$ & 3.54 \\
\hline $\begin{array}{l}\text { 9. Despite our special abilities, humans } \\
\text { are still subject to the laws of nature. }\end{array}$ & $27.99 \%$ & $50.18 \%$ & $16.75 \%$ & $4.13 \%$ & $1.31 \%$ & 3.99 \\
\hline $\begin{array}{l}\text { 10. The so-called “ecological crisis" } \\
\text { facing humankind has been greatly } \\
\text { exaggerated. }\end{array}$ & $2.61 \%$ & $10.01 \%$ & $23.21 \%$ & $51.41 \%$ & $13.13 \%$ & 3.63 \\
\hline
\end{tabular}




\begin{tabular}{|l|l|l|l|l|l|l|}
\hline $\begin{array}{l}\text { 11. The Earth is like a spaceship with } \\
\text { very limited room and resources. }\end{array}$ & $31.33 \%$ & $43.07 \%$ & $16.97 \%$ & $7.11 \%$ & $1.89 \%$ & 3.95 \\
\hline $\begin{array}{l}\text { 12. Humans were meant to rule over } \\
\text { the rest of nature. }\end{array}$ & $4.64 \%$ & $12.18 \%$ & $28.50 \%$ & $36.55 \%$ & $18.49 \%$ & 3.52 \\
\hline $\begin{array}{l}\text { 13. The balance of nature is very } \\
\text { delicate and easily upset }\end{array}$ & $16.24 \%$ & $48.44 \%$ & $25.67 \%$ & $8.63 \%$ & $1.38 \%$ & 3.70 \\
\hline $\begin{array}{l}\text { 14. Humans will eventually learn } \\
\text { enough about how nature works to be } \\
\text { able to control it. }\end{array}$ & $5.80 \%$ & $20.74 \%$ & $33.87 \%$ & $31.62 \%$ & $8.34 \%$ & 3.17 \\
\hline $\begin{array}{l}\text { 15. If things continue on their present } \\
\text { course, we will soon experience a } \\
\text { major ecological catastrophe. }\end{array}$ & $44.74 \%$ & $41.33 \%$ & $11.46 \%$ & $1.96 \%$ & $0.87 \%$ & 4.27 \\
\hline
\end{tabular}

Table 3 NEP Answers

Female students (NEP mean = 3.65) scored slightly higher than male students (NEP mean $=3.61)$. Local school students $($ NEP mean $=3.66)$ scored higher than international school students $($ NEP mean $=3.51)$. Students with a higher NEP score were significantly more likely to turn off their air conditioning when leaving the house $\left(r^{2}=0.48 ; p=\right.$ 0.049), echoing findings of our earlier study (Jackson et al., 2016).

\section{Interviews}

As seen from Tables 4 and 5, local school students showed concern with climate change and reported related environmental-friendly behaviours such as recycling and reducing energy use. However, junior students were less aware in contrast to senior counterparts. On the other hand, all students from the international school showed awareness of local and global climate change issues, and reported a greater variety of related environmental-friendly behaviours that included: recycling, limiting energy consumption, organising student-led in-school energy monitoring associations, vegan diet, and urging the school to install a thermal energy generator. Compared to counterparts in local schools, junior students in international school were more aware of 
climate changes on both local and global levels. Senior students from local and international schools showed similar levels of awareness and understanding.

\begin{tabular}{ccccc} 
Student Attitude and Awareness & \multicolumn{2}{c}{ Local School } & \multicolumn{2}{c}{ International School } \\
& $\begin{array}{c}\text { Form 1-3 } \\
(\mathrm{n}=13)\end{array}$ & $\begin{array}{c}\text { Form 4-6 } \\
(\mathrm{n}=9)\end{array}$ & $\begin{array}{c}\text { Grade 7-9 } \\
(\mathrm{n}=4)\end{array}$ & $\begin{array}{c}\text { Grade 10-12 } \\
(\mathrm{n}=8)\end{array}$ \\
\hline$\underline{\text { Aware of local climate changes }}$ & $\underline{54.0 \%}$ & $\underline{100 \%}$ & $\underline{100 \%}$ & $\underline{100 \%}$ \\
Gave 1-3 examples only & $54.0 \%$ & $22.2 \%$ & $75 \%$ & $12.5 \%$ \\
Gave more than 3 examples & $0 \%$ & $77.8 \%$ & $25 \%$ & $87.5 \%$ \\
Aware of global climate changes & $\underline{31.0 \%}$ & $\underline{100 \%}$ & $\underline{100 \%}$ & $\underline{100 \%}$ \\
Gave 1-3 examples only & $31.0 \%$ & $22.2 \%$ & $50 \%$ & $12.5 \%$ \\
Gave more than 3 examples & $0 \%$ & $77.8 \%$ & $50 \%$ & $87.5 \%$ \\
Aware of human impact on climate change & $85.0 \%$ & $100 \%$ & $100 \%$ & $100 \%$ \\
\hline
\end{tabular}

Table 4 Students' self-reported attitudes toward and awareness of climate change in interviews

Student Behaviour

No Behaviour

Leader of climate change related societies/program in school

Member of climate change related societies/program in school

Participate in climate change related programmes outside school

Recycling

Reduce energy consumption

Use less air conditioning

Refuse environmentally unfriendly products

Reuse

Use of organic products

Vegan/Vegetarian
School Type

$\begin{array}{cc}\text { Local } & \text { International } \\ (\mathrm{n}=22) & (\mathrm{n}=12)\end{array}$

$\begin{array}{ll}5 \% & 0 \% \\ 0 \% & 25 \% \\ 0 \% & 50 \% \\ 1 \% & 17 \% \\ 32 \% & 42 \% \\ 90 \% & 83 \%\end{array}$

$\begin{array}{ll}1 \% & 42 \% \\ 1 \% & 33 \% \\ 0 \% & 17 \% \\ 0 \% & 17 \%\end{array}$

Table 5 Percentage of students reporting environmental-friendly behaviour to respond to climate change in interviews (tables corrected to the nearest decimal place) 
As seen from interview excerpts, although awareness of climate change varied across junior students in local and international schools, their feelings about local climate change were quite similar.

When I was younger the local climate was much cooler; it was cooler in the summer and much colder in the winter...the summers in the past were not as stuffy. Nowadays we also smell the waste emitted by cars, and since it's also much hotter, I feel much more distressed. It's very stuffy and very humid... (F3, Student $A$ )

I mean aside from that one time recently when Hong Kong was like 4 degrees, the winters weren't as cold...you can tell, there wasn't really a need to wear really warm clothes, or anything. (G9, Student C)

When asked about the future trend of global climate change, the answers of junior students in local school were less elaborate than those in international school.

Local school:

The temperature will exceed 50 degrees. (F1, Student A)

I think if we don't start making remedies now, however powerful the technologies in the future cannot save the environment and climate. (F3, Student B)

International school:

Because like - we are really wasting resources we have right now, and then pollution is increasing - global warming is getting worse; so I watched this-video-it's like it shows how if the global warming keeps on getting worse, then it affects the whole season and the disasters, it shows how some cities even got drowned; it's a future...It's a bad future, that's all I know. (G9, Student B)

For senior students, no significant differences between local and international schools

were observed. Both groups' elaborations were quite sophisticated.

Has the climate changed... well I think locally we are all familiar with the example of Hong Kong... a few months ago in January, the temperature reached the new lowest record... for how many years was it? I forgot. These are the extremes we are having; it means that summers are getting hotter and winters are getting colder. I think this climate change is globally-caused, probably due to some human activity like deforestation, and exploitation of resources... industrial development had caused global warming, and there are going to be more heat and cold waves...the balance of temperature had tipped off... it had exceeded the earth's capacity... global warming is going to continue...glaciers will melt. (F5, Student D) 
When asked about climate change in the future, students from both schools shared similar viewpoints:

I think as for now both the climate and environment are not at their worsts, but if humans continue to live the way they do now, without doing any remedial work, the environment would only get even worse. Exploitation of resource, overusing resource, creating pollutants wasting water... all these would only make the climate more extreme, the environment even worse. (F4, Student C)

I remember when I was younger I once attended a talk, and the speaker said that if every glacier on the earth melted, sea level would rise by 6 meters... horrifying. But as for the future, I guess it will be fine. I think a lot of countries and their leaders are aware of the problem and are making an effort to change, say reducing emission or waste...so I guess the future is going to be bright, because at least we are aware of what's wrong. (F5, Student C)

The most distinctive contrast between students from local and international school was the action taken by the students to combat climate change. Students from international school seemed more proactive and organized.

Local school:

We don't use either AC or heater at home, we only use fans. The AC drains too much energy - it makes the electricity bill look horrible, so we only use fans. (F1, Student B)

Use less paper towels, greening home by planting plants; on climate aspect, I try to use as little air conditioning as possible, because the use of air conditioners emits hot air; I mainly use fans. (F4, Student D)

Sometimes my heart is willing but my abilities are lacking...I know what I need to do, what I should do, and how terrible the situation we are in is... but as you think about these things you might also feel suffocated at home... it's now 32 degree Celsius and I don't think anyone can survive that without air conditioner...my family keeps the air conditioner on 24/7...I feel bad about this. But I always recycle and categorize my trash. Really it's often easy to preach and hard to practice. (F5, Student B)

International school:

My brother founded Green Guardians... I am a member and have been doing it four years. It's progressed a lot. We started off mostly doing recycling, so we have paper recycling bins in each classroom, and we'll collect them and throw into the collection bin...I think at that time when it was founded, or when I joined it, the most concerning issues were paper and also airconditioning... so those were the two projects that we've basically implemented in our school. Now we've worked... to promote people travelling by bikes... because in our school, every morning and after school there's a lot of mostly unnecessary cars. It not only creates traffic, but contributes to air pollution. (G11, Student A) 
At school, as I mentioned before, at the primary building rooftop, we're building quite a lot of modules of solar panels, which we're going to connect to one classroom. It's part of the learning experience as well, so students can go into the classroom and experience when there's no output in solar panels, to raise awareness for students as well. So in conjunction with that, we're also building a mini renewable energy education center, which has various kinds of renewable energy. We're still planning these, and I'm part of designing this as well. (G11, Student E)

Reported teaching approaches in local and international schools were different.

According to interviews, teachers in local school tended to use more lecturing to instill

knowledge and concepts, whereas those in international school seemed to use more approaches to enhance experiential learning and engage students actively in organized activities.

I always remind my students: turn off the lights, the AC; because I am aware of the deteriorating environment, that is why I remind my students to be observant, and teach them news from the outside... There are three-colored recycling bins in the school. I always remind my students to throw read newspapers...or used plastic bottles into the recycling bins. Students usually aren't very proactive in recycling; I often see them throwing plastic bottles into regular rubbish bins. That is why I try to remind them, usually once every week after school...I guess experiential learning is what is lacking. (Local School, Teacher 2)

There's also petitions coming around for Hong Kong... when I hear about them I send them to all the students in the classes that I teach and say if you feel like this is something you are interested in, how about you read through, add some comments, sign it, you never know, little petitions can mean something... (International School, Teacher 1)

Local and international teachers reported using different approaches or foci in assessing student's awareness of climate change issues. Local teachers agreed that students' understanding of relevant topics, as exhibited in their assignments and/or examination performance, served as the best means of assessment. International school teachers, on the other hand, stated that they believed personal behavioural change was the only criterion to assess students' awareness; examination and coursework was not mentioned.

The easiest way is through assignment and assessment - whether the student grasps the idea is revealed by how he or she answers the question. If it's accurate, I would say they are literate. (Local School Teacher 1) 
Through exams, assignments, and student assessment - that's about all we can do. (Local School, Teacher 2)

I guess there is obviously the personal change, like personal behavior change, rethinking consumption habits of all different kinds of materials and goods, be advocate, paying attention to current events and what's happening... (International School, Teacher 2)

\section{Discussion}

In contrast with research suggesting that China and Hong Kong tend to have less environmental and climate change concern in comparison with western societies (Hills, 2005; Chen, Lee \& Stevenson, 1995; Liu, Ouyang, \& Miao, 2010), results of this study indicate the opposite. The mean NEP score was relatively high in our sample; notably higher than those measured in Israel and New Zealand, for example (Gottlieb, VigodaGadot, \& Haim, 2013; Shephard et al., 2009). Hong Kong secondary students seemed to demonstrate a high level of awareness of and positive attitudes towards climate change issues when compared to participants in other parts of the world. On the other hand, our findings are suggestive in relation to methodological questions raised by Lee and colleagues (2002) about using Likert scales in Asian contexts, and the possibility that research participants in Asian societies may tend to answer positively-worded questions more extremely and positively than negatively-worded questions.

When examining the possible differences between students who come from local and international schools in Hong Kong, we found that junior students in international schools seemed to be more aware of climate changes on both local and global levels, when compared to their counterparts in local schools. Senior students from local and international schools did not have significant difference in their levels of awareness and understanding of climate change issues. 
Nevertheless, during interviews, international school students appeared to be more proactive and organized in combatting climate change than their counterparts in local school. This might be partly attributed to the different curricula taken as well as different teaching approaches and assessment methods adopted by teachers. The analysis of the local curriculum and IB curriculum showed that the former contains richer content on CCE and has more lesson time, and the teaching strategy adopted is more direct instruction. Conversely, the IB programme contains less content, but devotes more time in investigative and experiential learning of CCE topics. It seems that the teaching strategy adopted by teachers have an impact on student learning within the context of CCE, which lends support to Yeung's (2001) study that enquiry teaching is more effective than a didactic approach for developing environmental understanding in the short run. However, to maximize the effectiveness of enquiry teaching of CCE in local schools, it is important to call for a fundamental change in the high-stake public examinations of Hong Kong, with a greater emphasis on enquiry and investigation. At the same time, teacher training for both pre- and in-service teachers is needed to support teachers for a paradigm shift in pedagogy.

As argued by Zhu, Douglas and Savelyeva (2014), the newly introduced core subject at the senior secondary level of the local curriculum, namely Liberal Studies, provides new possibilities for enhanced CCE in secondary and higher education. However, it seems these possibilities are not being explored in depth. As in Dalelo's (2011) study of climate change education and curriculum in Ethiopia, the politics of climate change and what people can do to combat it may not as clear to students when local curriculum is taught in disciplinary, if systematic method (see also Chang, 2012). Our findings suggest that students across the curriculum are open to environmental concerns. However, teachers who are less open to a political and controversial approach 
to climate change education may be less effective, as we compare the students' and teachers' attitudes about climate change education across the local and international schools. As Seow and Ho note (2016), teachers' views about introducing climate change controversies and their related views of students' capacities can have a major impact on their approaches and the effectiveness of their lessons. Even when students are encouraged to consider controversies and their own behaviors related to climate change, they may still fail to see its relevancy to their own lives, seeing it as a fad, if their teachers' understanding and treatment of the topic obscures its social relevance (Chang, 2015; Dal et al., 2015; Ozdem et al., 2014).

Conclusion

CCE is a critical element of education, particularly in Hong Kong, where pollution and climate change demonstrably threaten human health and livelihood. Though Hong Kong schools have seen waves of reform emphasizing CCE over the decades, little research has scanned student outcomes such that the efficacy of reforms might be considered. This paper reported on findings of the first major study of schoolexiting young people's sustainability attitudes in Hong Kong. The findings also indicate the possibility of methodological issues with using Likert scales in East Asia.

Nonetheless they provide a baseline for cross-national studies, and show significant correlations between student attitudes and behaviors worth further and more holistic exploration. Qualitative follow-up study revealed different experiences, behaviors, and levels of awareness related to CCE by school type, as expressed in the voices of students themselves, as well as their teachers, and as indicated by the analysis of curricula guidelines. More research is needed that focuses on issues both curricular and 
methodological in East Asian education contexts, as we work to improve CCE to improve global sustainability.

\section{Acknowledgments}

The authors wish to thank Monica Soong for assistance with translation, as well as research assistants Sean Cain, Emma Brown, and Tim Cheng. This research was funded by the Seed Funding Programme for Basic Research (Grant No. 201410159031), University of Hong Kong.

\section{References}

Bamberg, S., \& Möser, G. (2007). Twenty years after Hines, Hungerford, and Tomera: A new meta-analysis of psycho-social determinants of pro-environmental behaviour. Journal of Environmental Psychology, 27(1), 14-25.

Boeve-de Pauw, J., Donche, V., \& Van Petegem, P. (2011). Adolescents' environmental worldview and personality: An explorative study. Journal of Environmental Psychology, 31, 109-117.

Chan, T. B. and Chai, L. T. (2010). “Attitude towards the environment and green products: consumers' perspective", Management Science and Engineering, Vol. 4, pp. 27-39.

Chang, C.-H. (2015). Teaching climate change - a fad or a necessity? International Research in Geographic and Environmental Education, 24(3), 181-183.

Chang, C.-H. (2012). The changing climate of teaching and learning school geography: The case of Singapore. International Research in Geographic and Environmental Education, 21(4), 283-295. 
Chang, C.-H., \& Pascua, L. (2015). Singapore students' misconceptions of climate change. International Research in Geographic and Environmental Education, 25(1), 84-96.

Chen, C., Lee, S.-Y., \& Stevenson, H. W. (1995). Response style and cross-cultural comparisons of rating scales among East Asian and North American students. Psychological Science, 170-175.

Cheung, L. T. O., Fok, L., \& Gou, G. R. (2016). Students' academic performance in environmental studies: An empirical study of different groups of secondary school graduates. International Research in Geographical and Environmental Education [online first].

Dal, B., Alper, U., Ozdem-Yilmaz, Y., Ozturk, N., \& Sonmez, D. (2015). A model for preservice teachers' climate change awareness and willingness to act for pro-climate change friendly behavior: Adaptation of awareness to climate change questionnaire. International Research in Geographic and Environmental Education, 24(3), 184-200.

Dalelo, A. (2011). Global climate change in geography curricula for Ethiopia secondary and preparatory schools. International Research in Geographic and Environmental Education, 20(3), 227-246.

Dunlap, R. E. (2008). The new environmental paradigm scale: From marginality to worldwide use. The Journal of Environmental Education, 40(1), 3-18.

Dunlap, R. E., Van Liere, K. D., Mertig, A. G., \& Jones, R. E. (2000). New trends in measuring environmental attitudes: measuring endorsement of the new ecological paradigm: a revised NEP scale. Journal of social issues, 56(3), 425-442. 
Friesen, L., \& Gangadharan, L. (2013). Designing self-reporting regimes to encourage truth telling: an experimental study. Journal of Economic Behavior E Organization, $94,90-102$.

Gottlieb, D., Vigoda-Gadot, E., \& Haim, A. (2013). Encouraging ecological behaviors among students by using the ecological footprint as an educational tool: A quasiexperimental design in a public high school in the city of Haifa. Environmental Education Research, 19(6), 844-863.

Hawcroft, L. J., \& Milfont, T. L. (2010). The use (and abuse) of the new environmental paradigm scale over the last 30 years: A meta-analysis. Journal of Environmental Psychology, 30, 143-158.

Hills, P. (2005). Environmental reform, ecological modernization and the policy process in Hong Kong: an exploratory study of stakeholder perspectives. Journal of Environmental Planning and Management, 48(2), 209-240.

Hunter, L.M., Hatch, A. and Johnson, A. (2004). “Cross-national gender variation in environmental behaviors", Social Science Quarterly, Vol. 85 No. 3, pp. 677-694.

Jackson, L. (2016). Education for sustainable development: From environmental education to broader views. In Handbook of Applied Learning Theory and Design in Modern Education, eds. Elena Railean, Gabriela Walker, Atilla Elci, \& Liz Jackson. Hershey, PA: IGI Global, 42-65.

Jackson, L., Pang, M.-F., Brown, E., Cain, S., Dingle, C., \& Bonebrake, T. (2016). Environmental Attitudes and Behaviors among Secondary Students in Hong Kong. International Journal of Comparative Education and Development [in press]. 
Kaiser, F. G., Wolfing, S., \& Fuhrer, U. (1999). Environmental attitudes and ecological behavior. Journal of Environmental Psychology, 19, 1-19.

Kitayama, S., Markus, H. R., Matsumoto, H., \& Norasakkunkit, V. (1997). Individual and collective processes in the construction of the self: self-enhancement in the United States and self-criticism in Japan. Journal of Personality and Social Psychology, 72(6), 1245.

Lai, C.-1. J., Brennan, A., Chan, H.-m., \& Tao, J. (2003). Disposition toward environmental hazards in Hong Kong Chinese: Validation of a Chinese version of the environmental appraisal inventory (EAI-C). Journal of Environmental Psychology, 23(4), 369-384.

Lee, J. W., Jones, P. S., Mineyama, Y., \& Zhang, X. E. (2002). Cultural differences in responses to a Likert scale. Research in Nursing \& Health, 25(4), 295-306.

Liu, Y., \& Constable, A. (2010). ESD and lifelong learning: A case study of the Shangri-la Institute's current engagement with the Bazhu community in Diqing, China. International Review of Education, 56(2), 271-285.

Liu, J., Ouyang, Z., \& Miao, H. (2010). Environmental attitudes of stakeholders and their perceptions regarding protected area-community conflicts: A case study in China. Journal of environmental management, 91(11), 2254-2262.

Ozdem, Y., Dal, B., Ozturk, N., Sonmez, D., \& Alper, U. (2014). What is that thing called climate change? An investigation into the understanding of climate change by seventh-grade students. International Research in Geographic and Environmental Education, 23(4), 294-313. 
Salehi, S., Nejad, Z. P., Mahmoudi, H., \& Burkart, S. (2016). Knowledge of global climate change: View of Iranian university students. International Research in Geographic and Environmental Education, 25(3), 226-243.

Seow, T., \& Ho, L.-C. (2016). Singapore teachers' beliefs about the purposes of climate change education and student readiness to handle controversy. International Research in Geographic and Environmental Education, 25(4), 358-371.

Scott, D., \& Willits, F. K. (1994). Environmental attitudes and behavior a Pennsylvania survey. Environment and Behavior, 26(2), 239-260.

Shephard, K., Mann, S., Smith, N., \& Deaker, L. (2009). Benchmarking the environmental values and attitudes of students in New Zealand's post-compulsory education. Environmental Education Research, 15(5), 571-587.

Stemler, S. (2001). An overview of content analysis. Practical Assessment, Research $\mathcal{E}$ Evaluation, 7(17).

Subramanian, N., Abdulrahman, M. D., Wu, L., \& Nath, P. (2015). Green competence framework: evidence from China. Journal of Human Resource Management [online first].

Tsang, E. P.-K., \& Lee, J. C.-K. (2014). ESD projects, initiatives and research in Hong Kong and Mainland China. In Schooling for Sustainable Development Across the Pacific (pp. 203-221): Springer.

UNESCO. (2010b). UNESCO strategy for the second half of the United Nations decade of education for sustainable development. Paris, France: Author. 
Vare, P., \& Scott, W. (2007). Learning for a change exploring the relationship between education and sustainable development. Journal of Education for Sustainable Development, 1(2), 191-198.

Vikan, A., Camino, C., Biaggio, A., \& Nordvik, H. (2007). Endorsement of the New Ecological Paradigm: A comparison of two Brazilian samples and one Norwegian sample. Environment and Behavior, 39(2), 217-228.

Wong, N., Rindfleisch, A., \& Burroughs, J. E. (2003). Do reverse-worded items confound measures in cross-cultural consumer research? The case of the material values scale. Journal of Consumer Research, 30(1), 72-91.

World Bank (2010). Public attitudes toward climate change: Findings from a multi-country poll. World Bank.

Yeung, P-M. S. (2001). An empirical study of the influence of teaching approaches and academic ability on students' understanding of environmental issues in Hong Kong, International Research in Geographic and Environmental Education, 20(3), 260-283.

Zhu, J.-X., Douglas, W., \& Savelyeva, T. (2014). Effects of liberal studies on Hong Kong students' environmental knowledge and behaviour. Hong Kong: Centre for Lifelong Learning Research and Development, The Hong Kong Institute of Education. 